\title{
Superannuation Tax Reform: Fiscal Consequences
}

\section{Sinclair Davidson and Ross Guest}

I $\mathrm{n}$ his 2006 Budget speech, Treasurer Peter Costello announced 'the most significant change to Australia's superannuation system in decades'. The reform objectives were to 'sweep away the current complexity faced by retirees, increase retirement incomes, give greater flexibility as to how and when superannuation can be drawn down, and improve incentives for older Australians to stay in the workforce' (Costello, 2006). These four objectives were motivated by the broader economic challenges of population ageing, insufficient savings by the baby boomer generation, and a shortage of skilled workers. We focus on the announcement that, from 1 July 2007, income from a taxed superannuation fund would not be taxable for individuals aged over 60 . What was not announced in the budget, nor subsequently announced, is the expected budget cost of these reforms, and it is this particular aspect of the reforms that we investigate here.

Superannuation assets have been projected to more than double in real terms between 2005 and 2020 (IFSA, 2007), compared with an increase in real GDP in the order of 60 per cent (at 3 per cent compound growth) over the same period. Hence the ratio of superannuation assets to GDP could nearly double in this period. There are several reasons for this growth. IFSA (2007) reports a study suggesting that 23 per cent of this growth can be attributed to the changes introduced in the 2006 Budget. Other factors include: the cumulative effect of the 9 per cent compulsory contribution rate that has applied since July 2002; the growing awareness of the benefits of superannuation and its increasing flexibility; and an older workforce.

Given this context, simply extrapolating the current revenue from the superannuation exit (or benefits) tax would not be appropriate as it would not allow for increased contributions leading to increased superannuation assets. We first consider the budgetary costs if voluntary contribution rates were to increase after 2007. Under our assumptions (explained below) budgetary costs would be around one per cent of GDP (around $\$ 10$ billion). We then consider the budgetary costs of the concessional treatment of superannuation benefits and contributions. These costs are potentially much larger, amounting to several per cent of GDP.

The Productivity Commission (2005) indicated that government revenue as a share of GDP was not sensitive to an aging population and was projected to remain stable over the next 40 years, but also indicated that spending would increase by about six per cent of GDP given current policy and private sector behaviour. Following the superannuation reforms we show that this figure could blow out by an additional one per cent of GDP. Our results also suggest that the

Sinclair Davidson is Professor of Economics, School of Economics, Finance and Marketing, RMIT University, and Ross Guest is Professor of Economics, Griffith Business School, Griffith University. 
fiscal costs of ageing could be reduced substantially by (partially) eliminating the tax concessions on superannuation benefits.

An important qualification concerns our assumption about superannuation coverage by age group. The number of individuals with superannuation in each age group is assumed to increase with their population growth rates. Hence the rate of coverage of workers by age group remains constant. This underestimates the extent of superannuation coverage in future decades because the superannuation coverage of older workers, especially, will be higher than it is today. This has two opposite fiscal implications. It implies an underestimate of the fiscal cost of the tax concessions on superannuation; but it ignores the budgetary savings from reduced pension eligibility due to higher rates of superannuation coverage. We ignore these opposing fiscal effects, as does the Institute of Actuaries of Australia (IAA, 2006) in their analysis. We (and the IAA) also ignore other general equilibrium effects of lower superannuation taxation that could affect government tax revenue - in particular we ignore any response of labour supply or personal saving and therefore any effect on rates of capital accumulation and economic growth. We acknowledge that these effects may not be trivial but leave them for future work.

\section{Background: Taxes on Superannuation}

Australia's superannuation system rests on 'three pillars': a means-tested age pension financed on a 'Pay-As-You-Go' basis, and two private superannuation components - the first financed by a compulsory employer contribution of nine per cent of salary, and the second by voluntary contributions. Most industrial economies follow a similar policy framework. Where Australia has differed from other economies is in the taxation aspects of superannuation.

Currently in Australia income flows relating to superannuation are taxable at three stages: on pre-tax income contributed to the fund, on income generated from assets held in the fund, and on income withdrawn from the fund - an 'exit' tax. The exit tax in Australia is designed specifically to provide a disincentive to lump sum withdrawals. In particular, the government wished to avoid asset dissipation or 'double-dipping', which can occur when retirees spend all their lump sum benefits on consumption in order to qualify for the age-pension. This system of taxing income flows at all three stages is sometimes described as a TTT system (the three T's denoting the three stages at which income is taxed); see Whitehouse (1999). Other combinations used in OECD countries are: TTE, where tax is levied on the way into the fund and while in the fund, but at a zero per cent on the way out; ETT, where income on the way into the fund is tax-exempt, but taxable while earned from assets in the fund and taxable on the way out; EET, where income on the way into the fund and on earnings while in the fund are both tax-exempt, but income on the way out is taxable. As of 2002 Australia was the only OECD country to adopt the TTT system (Horne, 2002). Among OECD economies, the EET model is the most common, where contributions and earnings are tax-free but benefits are taxable. Following the Budget announcement, Australia will have a TTE model. In the appendix we show some simple algebra demonstrating the equivalence of the TTE model and the ETT models under certain assumptions. 
The Senate Select Committee on Superannuation in 2002 investigated three questions: Is the structure of taxation at present appropriate? How can retirement incomes be increased? How does the superannuation system impact on the work-retirement decision? The Committee's recommendations included the phasing out of contributions and end-benefits taxes, exploration of methods to encourage older workers to remain in the workforce, and simplification of the superannuation system. The government's response was minimalist, and most of the recommendations, including the phasing out of the contributions tax, were rejected. Many commentators, however, continued to call for the abolition of the contributions tax. In early 2006, Senator Nick Minchin proposed the abolition of contributions tax to promote greater savings into superannuation (Marris, 2006). Media speculation indicated that this proposal would 'cost' the government about $\$ 3.3$ billion per annum, but only deliver an additional $\$ 30$ per week to retired workers (Anderson and Allen, 2006). This additional income would occur in the future, but have little impact on those individuals likely to retire in the near future.

Much of the complexity surrounding superannuation taxation relates to the exit taxes. As taxes have been introduced, existing contributions to superannuation have been 'grandfathered' in place. Appendix 13 of the Senate Select Committee (2002) sets out the 'grandfathered' provisions. Without appropriate arrangements the tax consequences of retirement can be onerous. For example, Treasury (2006:2) has calculated that a lump-sum payment could consist of 'up to eight different parts taxed in seven different ways'. Many retirees therefore incur high financial planning fees in order to organise their affairs. In its response to the Senate Select Committee, the government had indicated it was 'mindful of the need to reduce complexity in superannuation' (Commonwealth Government, 2005:17). Treasury (2006) also indicated that the greatest component of complexity in superannuation was the taxation of end-benefits. In his budget speech, Peter Costello indicated that eliminating exit taxes 'would be the most direct way of cutting through the complexity of the current system'.

Apart from reducing complexity, there are other arguments in favour of eliminating the benefits tax and hence shifting from a TTT model to a TTE model. It increases the disposable income of those baby-boomers who are about to retire and therefore addresses the problem, as perceived by the 2002 Senate Select Committee, of inadequate retirement savings of this generation. It may encourage older workers to either remain in the work force or re-enter the work force by effectively raising their after-tax wage and therefore raising their price of leisure, providing that the income effect does not outweigh the substitution effect on their demand for leisure. Also, incentives encouraging voluntary increases in superannuation contributions arguably result in lower deadweight losses than an increase in compulsory superannuation contributions.

The fiscal implications of shifting from a TTT to a TTE model depend largely on two factors: the future age distribution of the population, and changes in voluntary superannuation contributions. We next consider the first of these issues: population ageing, beginning with some background about the role of superannuation in the context of population ageing. 


\section{Population Ageing and Superannuation}

Like most OECD countries, Australia's population is ageing due to the demographic transition associated with advanced economic development. The demographic transition comes in stages, starting with declining infant mortality and increases in adult life expectancy, followed later by declining fertility rates. The decline in fertility rates in most OECD countries was accentuated by the earlier 'baby boom' - the jump in fertility rates associated with the end of World War II. The demographic transition and the post war baby boom has created a temporary bulge in the age distribution that will take several decades to wash out (see Bloom et al, 2003; Jackson and Felmingham, 2004). In Australia, the old age dependency ratio (those aged $65+$ as a proportion of the total population) is expected to roughly double between now and 2050 to between 24 per cent and 28 per cent depending on assumptions (ABS Catalogue 3222.0). This implies a falling employment to population ratio, which, in turn, implies a fall in per capita consumption (living standards) growth below labour productivity growth in the absence of behavioural changes by workers and consumers or policy changes by government (see Guest and McDonald, 2002 for a full discussion). Such changes would have to imply an increase in labour force participation rates (LFPRs) of older workers or an increase in the rate of national saving.

The introduction of compulsory superannuation, in 1992, can be seen as an attempt by the Government to offset the effect on future consumption of a declining employment to population ratio. It serves another purpose from the Government's perspective, which is to reduce the calls on the Federal Budget due to rising old-age pension liabilities. The Productivity Commission (2005) has estimated these liabilities would rise by 1.7 per cent of GDP between 2004 and 2045 in the absence of behavioural or policy changes. The increase in the rate of compulsory superannuation to the current rate of nine per cent is intended to mitigate this growth in pension spending and is consistent with the shift in other OECD countries to pre-funding of old age pensions. However, this rate is unlikely to provide adequate retirement income even in the long run. The Australian Superannuation Funds Association has calculated that a nine per cent contribution rate over 40 years would generate a pre-tax replacement income ratio of 40 per cent (Horne, 2002). This is less than the 60-65 per cent of pre-retirement gross income, or (equivalently) 70-80 per cent of pre-retirement expenditure recommended by the Senate Select Committee (Senate Select Committee, 2002:40). The Commonwealth Government's response to the Commission's report made it explicit that they do 'not support setting a replacement rate target', yet its own modelling on the current superannuation structure would yield a rate similar to the Senate recommendation (Commonwealth Government, 2005:1).

One policy option in order to increase the replacement rate would be to increase the compulsory contribution rate, but this would be of dubious merit. As argued in Guest and McDonald (2002) compulsory superannuation contributions can reduce national economic welfare in two ways. The first round welfare loss arises from the liquidity constraint on optimal consumption smoothing, at least for low-income earners, and from the distortion to choices of saving vehicles for highincome earners. Compulsory superannuation causes a second round welfare loss 
by imposing a tax on employment (Freebairn, 1998). A better approach, arguably, is to provide tax incentives for voluntary superannuation contributions such as those announced in the 2006 Budget (although these imply other welfare losses in the form of deadweight losses arising from tax expenditures).

As noted above, the additional aim of the 2006 Budget changes relating to superannuation was to increase the LFPRs of older workers to offset the burden of population ageing. The new rules could make it more attractive for individuals to remain in the workforce after age 60 and to continue saving into superannuation. Benefits paid from a superannuation fund to those over the age of 60 will be taxfree, which could boost LFPRs depending on the strength of the income and substitution effects. But importantly, individuals will be able to continue working and contribute up to $\$ 50,000$ per annum to a superannuation fund, at the concessional rate, until age 75 . That is, someone over the age of 60 could salary sacrifice up to $\$ 50,000$ into a superannuation fund and immediately draw on that money as a lump-sum paying only 15 per cent in (contributions) tax. The 2006 Budget proposal thereby creates an age-based flat income tax - those over the age of 60 , earning up to $\$ 50,000$, could reduce their marginal income tax rate from 30 per cent to 15 per cent. Individuals over the age of 60 earning more than $\$ 50,000$ could salary sacrifice that amount into superannuation, pay the 15 per cent contributions tax, and then pay the normal rates on their income in excess of $\$ 50,000$. This policy allows a substantial decrease in the average income tax rate for those over the age of 60 who remain in the workforce.

As Horne (2002:7) says, however, superannuation policy options 'cannot be considered in isolation without reference to ... their long-run budget costs', which is the issue to which we now turn.

\section{The Fiscal I mpact of the Decision to Abolish the Exit Tax}

The IAA (2006) suggests that the long-run fiscal cost of the 2006 Budget proposal is likely to be low. The IAA points out that the benefits tax currently raises very little revenue. This may be due to, at least, three factors. The exit tax acts as a disincentive for retirees to take their superannuation as a lump sum. In addition, for funds placed in super prior to 1983 only five per cent of the lump sum is taxable income; and individuals who entered the superannuation system after 1992 and who are now retiring would not have accumulated sufficient funds to exceed the tax-free threshold. The IAA calculates that the benefits tax raises 0.05 per cent of GDP in tax revenue (compared with the contributions tax which raises 0.5 per cent of GDP in tax revenue). Based on ATO data and the estimated revenue figures from the IAA, we estimate that only 13 per cent of superannuants would actually be liable for the benefits tax. The IAA concludes that the cost of eliminating the benefits tax would be small. This view, however, apparently ignores the potential for increases in contribution rates, which would increase benefits and therefore increase the fiscal cost of the tax concession on benefits.

Table 1 contains our estimate of income tax revenues potentially at risk. Using data from the ATO Taxation Statistics 2003/4 and demographic data from the ABS (Cat. 3201.0 and Cat. 3222.0) we have calculated the current income tax share of individuals aged over 60 in 2003/4. Assuming the tax shares remain 
constant and participation rates remain unchanged we estimate this age group's share of total income tax in future.

Table 1: Data for Population over 60 years of Age

\begin{tabular}{l|ccc}
\hline & Over 60s & \multicolumn{2}{c}{ Income tax paid by over 60s } \\
\hline & per cent of population & per cent of total income tax & per cent of GDP \\
2004 & 24.03 & 10.47 & 1.19 \\
2010 & 26.14 & 11.39 & 1.30 \\
2020 & 28.67 & 12.49 & 1.42 \\
2030 & 31.23 & 13.61 & 1.55 \\
2040 & 33.79 & 14.72 & 1.68 \\
2050 & 35.99 & 15.68 & 1.79 \\
\hline
\end{tabular}

We estimate that by mid-century the $60+$ age group would pay approximately 15 per cent of total income tax revenue under current policies and behaviour. In the most extreme case where all taxpayers in this age group convert all of their income into tax-free superannuation income, the loss of tax revenue would be 15 per cent of total income tax. As the Table indicates this would amount to 1.79 per cent of GDP, or around $\$ 18$ billion in today's dollars. Of course this is the limiting and perhaps hypothetical case. Nevertheless, given the ease of using the arrangements to generate income tax-free for the $60+$ age group, it is reasonable to expect the final outcome to be close to the limiting case.

\section{Calibrating a Base Case}

Our aim here is to project the size of various superannuation taxes given population projections and assumptions about future contribution rates. First we calibrate our calculations of the size of superannuation taxes in 2004 with those reported by the IAA (2006), both as a validity check and because we want to compare our projections with theirs.

Table 2 presents the base case data at 2004. It derives from ABS data (Cat. 6360.0 , Tables $1,10,15,16$ ) the following information by age group for the year 2000: the number of persons with superannuation; their annual contributions; and their median balances. We also use Australian Taxation Office data on mean income per age group (Taxation Statistics, 2003/4, Personal Tax, Table 12). We combine data from both of these sources to calculate mean superannuation contributions as a per centage of income per age group; see Table 2 Column 5.

The IAA (2006) calculates the following superannuation tax revenues as percentages of GDP for 2004: contributions tax 0.5 per cent, income tax (earned by the super funds) 0.2 per cent, and the benefits tax 0.05 per cent. Taking the contributions tax first, in order that our calculation of the contributions tax matches the IAA figure of 0.5 per cent we multiply the raw figures for superannuation contributions in Column 5 of Table 2 by a constant scaling factor for each age group. The resulting scaled super contributions are given in Column 5 of Table 2. For the benefits tax calibration, we first multiply the number of persons aged 55-64 who have superannuation $(744,000)$ by their median superannuation balance and multiply this by the 15 per cent benefits tax rate. 
This gives a raw figure for the benefits tax revenue, which would over-estimate the true figure because it would assume that all of the 55-64 year olds withdrew their superannuation and all of them paid the tax. ${ }^{1}$ So we calibrate by multiplying our raw figure by the fraction that gives the IAA figure of 0.05 per cent. This fraction is 13 per cent, which can be interpreted as the proportion of superannuants who in fact paid the benefits tax. For the income tax calibration, we need to estimate the income earned on assets held by the superannuation funds. For this we assume that income is earned at a (real) rate of 6 per cent of assets and that this income attracts the income tax rate of 15 per cent. The assets are calculated by multiplying the median superannuation balances by the number of persons with superannuation. These calculations give our raw figure for income tax revenue that we then calibrate to the IAA figure of 0.2 per cent by an adjustment factor (which turns out to be 1.71), which can be interpreted as the upward adjustment of the median super balances for each age group to the mean super balances.

Table 2: Age and Superannuation in 2003/ 4.

\begin{tabular}{|c|c|c|c|c|c|c|c|}
\hline \multirow[b]{2}{*}{ Age } & \multirow{2}{*}{$\begin{array}{c}\text { (1) } \\
\text { persons } \\
\text { with super }\end{array}$} & \multirow{2}{*}{$\begin{array}{c}\text { (2) } \\
\text { Super } \\
\text { contributions }\end{array}$} & \multirow{2}{*}{$\begin{array}{c}\text { (3) } \\
\text { Mean super } \\
\text { contribution }\end{array}$} & \multirow{2}{*}{$\begin{array}{c}(4) \\
\text { Mean income }\end{array}$} & \multicolumn{2}{|c|}{ (5) } & (6) \\
\hline & & & & & \multicolumn{2}{|c|}{$\begin{array}{l}\text { Mean super } \\
\text { contribution }\end{array}$} & $\begin{array}{c}\text { Median super } \\
\text { balance }\end{array}$ \\
\hline & & & & & \multicolumn{2}{|c|}{ per cent of income } & . \\
\hline & '000' & $\$ ' 000 / p . a$. & $\$ 000 / p . a$. & $\$ 1000$ & Raw & Scaled & $\$ 000$ \\
\hline $15-24$ & 1,330 & 277,212 & 208 & 19,103 & 1.09 & 3.44 & 1.02 \\
\hline $25-34$ & 2,279 & $1,857,388$ & 815 & 36,257 & 2.25 & 7.09 & 7.02 \\
\hline $35-44$ & 2,262 & $2,712,840$ & 1,199 & 43,553 & 2.75 & 8.69 & 12.76 \\
\hline $45-54$ & 1,886 & $2,823,548$ & 1,497 & 46,124 & 3.25 & 10.24 & 21.3 \\
\hline $55-69$ & 744 & $1,182,584$ & 1,589 & 39,820 & 3.99 & 12.59 & 29.96 \\
\hline
\end{tabular}

Notes

(1) ABS Cat. 6360.0, Table 1

(2) ABS Cat. 6360.0, Tables 15 and 16, taking the midpoints of the dollar ranges.

(3) $\mathrm{Col}(2) /(1)$.

(4) Taxation Statistics 2003/4, Personal Tax, Table 12, total (i.e. gross) income less pension income.

(5) Raw $=$ Col (3)/(4). Scaled $=$ Raw $*$ scaling factor such that Col $(2) * 0.15 *$ scaling factor $=0.5$ per cent of GDP.

(6) ABS Cat. 6360.0, Table 10, 'total superannuation balance' which gives the median balance. The median is scaled to the required mean value by a constant factor that ensures that the total earnings taxes $=0.2$ per centGDP.

Having calibrated our superannuation tax to GDP ratios for 2003/4 to those of the IAA (2006), we then project these out to 2050 based on the population projections used in Table 1 . In the first case, which we call the base case, we assume no change between 2004 and 2040 to the contribution rates used in Table 2 that were calibrated to the IAA tax revenue figures. Table 3 shows that our projected tax revenues from the three superannuation taxes are, not surprisingly, very close to those of the IAA (2006).

\footnotetext{
${ }^{1}$ An additional source of 'error' is that we use median superannuation balance instead of the mean in our calculation.
} 
The base case supports the IAA's main conclusion: the benefits tax will remain an insignificant source of revenue and therefore eliminating it would not impact significantly on total tax revenue. The earnings tax increases in relative importance due to the increased assets under management. The contributions tax revenue declines slightly in 2040 due to a relative decline in contributions as the working population declines.

\section{Alternative Scenarios: Higher Contribution Rates}

We then set up two alternative scenarios where the contribution rates of the older age groups are assumed to gradually increase up to the year 2025. In the first scenario, by 2025 15-34 year olds continue to pay 9 per cent into superannuation, but 35-44 year olds pay 12 per cent, 45-54 year olds pay 15 per cent and 55-69 year olds pay 20 per cent. In the second scenario, the contribution rates of older workers are assumed to increase even more: 15-24 year olds continue to pay 9 per cent into superannuation, 25-34 year olds pay 12 per cent, 35-44 year olds pay 15 per cent, 45-54 year olds pay 20 per cent and 55-69 year olds pay 30 per cent. The second scenario therefore exhibits a steeper increase in age-specific contribution rates than the first. However, even the second scenario is plausible. As does the first scenario, it assumes for example that 15-34 year olds continue to pay 9 per cent into superannuation. Only people over 34 years of age increase their contribution rates above the current statutory 9 per cent.

Table 3: Projections of Superannuation Taxes

\begin{tabular}{|c|c|c|c|c|c|c|}
\hline & \multicolumn{6}{|c|}{ Base Case } \\
\hline & \multicolumn{2}{|c|}{ Contributions tax } & \multicolumn{2}{|c|}{ Earnings tax } & \multicolumn{2}{|c|}{ Benefits tax } \\
\hline & \multicolumn{6}{|c|}{ (per cent of GDP) } \\
\hline 2004 & 0.50 & 0.50 & 0.20 & 0.20 & 0.05 & 0.05 \\
\hline 2025 & 0.45 & 0.51 & 0.43 & 0.45 & 0.21 & 0.19 \\
\hline \multirow[t]{3}{*}{2040} & 0.42 & 0.49 & 0.63 & 0.59 & 0.33 & 0.33 \\
\hline & \multicolumn{6}{|c|}{ Higher contribution rates: Scenario 1} \\
\hline & \multicolumn{2}{|c|}{ Contributions tax } & \multicolumn{2}{|c|}{$\begin{array}{l}\text { Earnings tax } \\
\text { (per cent of GDP) }\end{array}$} & \multicolumn{2}{|c|}{ Benefits tax } \\
\hline 2025 & \multicolumn{2}{|c|}{2.07} & \multicolumn{2}{|c|}{0.85} & \multicolumn{2}{|c|}{0.39} \\
\hline \multirow[t]{3}{*}{2040} & & & & & & \\
\hline & \multicolumn{6}{|c|}{ Higher contribution rates: Scenario 2} \\
\hline & \multicolumn{2}{|c|}{ Contributions tax } & \multicolumn{2}{|c|}{$\begin{array}{l}\text { Earnings tax } \\
\text { (per cent of GDP) }\end{array}$} & \multicolumn{2}{|c|}{ Benefits tax } \\
\hline 2025 & \multicolumn{2}{|c|}{2.75} & \multicolumn{2}{|c|}{1.00} & \multicolumn{2}{|c|}{0.48} \\
\hline 2040 & \multicolumn{2}{|c|}{2.58} & \multicolumn{2}{|c|}{2.25} & \multicolumn{2}{|c|}{1.03} \\
\hline
\end{tabular}

These alternative scenarios imply increases in superannuation assets and therefore in the benefits tax to GDP ratio (Table 3). In our first scenario, the 
benefits tax would raise 0.81 per cent of GDP in tax revenue by 2040, while in the second scenario it would raise 1.03 per cent in tax revenue of GDP. Our upper limit projection of 1.03 per cent of GDP may not be regarded as large but is considerably greater than the 0.05 per cent of GDP currently collected through the benefits tax (the figure according to the IAA). Our projected numbers need to be carefully interpreted. Without any increase in the contribution rate the benefits tax would have raised revenue of 0.33 per cent of GDP (the IAA figure and our figure). That revenue is now clearly foregone. Our higher figure of 1.03 per cent is based on the assumption that contribution rates would have increased anyway without the incentive of the benefits tax exemption, for reasons suggested in the introduction. A further qualification is that our projected foregone revenue ignores some labour supply effects and other general equilibrium effects. For example, the additional investments into superannuation would have incurred (greater) tax liability in their alternate investment vehicles. We have not calculated the tax revenue forgone from non-superannuation investment assets.

We now turn our attention to the benefit tax concessions that result in only a minority of beneficiaries actually paying the benefits tax (IAA, 2006). The calibration of our base case implies that the net effect of the concessional treatment of superannuation benefits is that only 13 per cent of retirees pay the benefits tax. We now remove the effect of the tax concessions and consider the superannuation revenue government would receive if all retirees paid a 15 per cent exit tax on their superannuation benefits. Results are shown in Table 4. The foregone revenue to government is now much larger - between 2.64 and 8.2 per cent of GDP depending on the assumptions about future contribution rates. The point of this exercise is to show the revenue that the government could have raised by doing in a sense the opposite of scrapping the exit tax, namely scrapping the tax-free threshold and taxing all superannuation benefits at 15 per cent. A clawing back of revenue of this magnitude would substantially offset the fiscal cost of population ageing which the Productivity Commission (2005) projects will amount to 6 per cent of GDP by 2045.

Table 4: Benefits Tax with No Exemptions or Concessions

\begin{tabular}{l|ccc}
\hline & 2003/ 4 Rates & Scenario 1 & Scenario 2 \\
\hline & & per cent of GDP & \\
2004 & 0.40 & 0.40 & 0.40 \\
2025 & 1.67 & 3.11 & 3.84 \\
2040 & 2.64 & 6.48 & 8.20 \\
\hline
\end{tabular}

Our final calculation is to consider the cost of the concessional rate of tax ( 15 per cent) on superannuation contributions and benefits. The 15 per cent tax rate on contributions and on benefits is below the marginal rate for most taxpayers. We project the cost of this concession by assuming no change to either current tax rules or the 2006/7 personal tax schedules, and reverting to the assumption in Table 2 that only 13 per cent of superannuants receive taxable benefits. Table 5 gives the results. The fiscal cost of the concessional tax rate on contributions would increase, from 2004 to 2040, from 0.48 per cent to as much as 2.49 per cent; and the fiscal cost of the benefits tax concessions would increase from 0.02 
per cent to 1.03 per cent. Both of these tax concessions could not be abolished because that would imply double taxation. But the fiscal cost of either of them is projected to increase substantially subject to our maintained assumptions.

Table 5: Total Cost of Superannuation Concessional Tax Rates

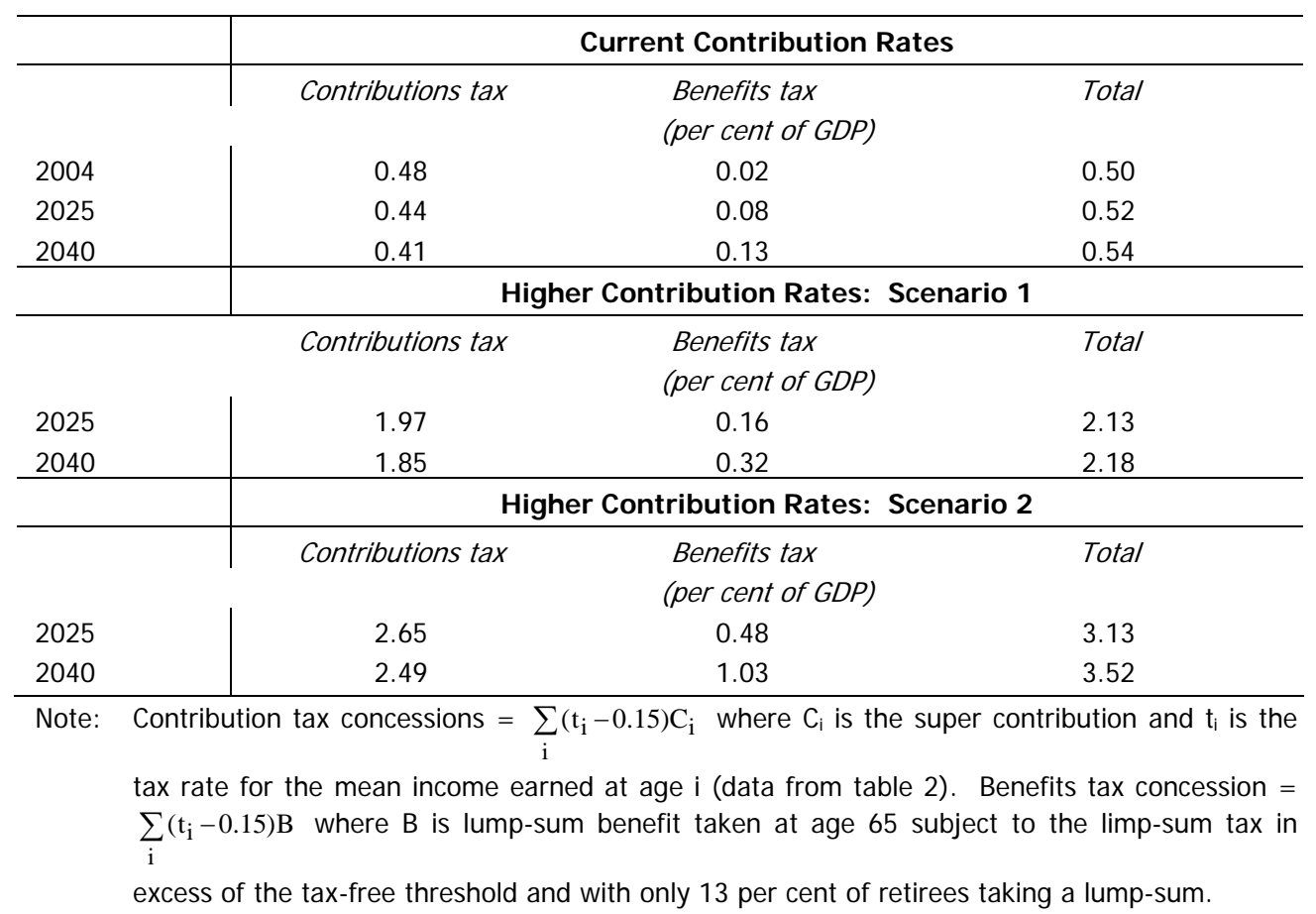

\section{Conclusion}

Our calculations indicate first that the revenue forgone from eliminating the superannuation benefits tax could be greater as a share of GDP in coming decades than now - in the order of one per cent of GDP (Table 3). This assumes that contribution rates would increase irrespective of the new tax concessions. Second, and more importantly perhaps, we show that the tax concessions that currently apply to contributions and benefits, in terms of tax-free thresholds on benefits and the low rate of 15 per cent, would become very substantial if individuals increase their contribution rates as expected (see Tables 4 and 5).

This conclusion is subject to the important qualifications that we noted. In particular, although we have allowed for demographic projections we have ignored future changes in the rates of superannuation coverage by age group, which as we said, are likely to have budgetary implications working in opposite directions. We also ignore general equilibrium effects through, for example, labour supply and national saving.

The analysis does not overturn some arguments in favour of eliminating the benefits tax that we also discussed above. Nevertheless, the potential size of future fiscal costs suggests that the policy changes announced in the 2006 Budget 
may well be revisited. This implies that the uncertainty surrounding superannuation policy is likely to continue.

\section{Appendix}

Some simple algebra can illustrate that the TTE and ETT cases yield identical values of superannuation assets at retirement, and therefore identical tax revenue in the long run, in a hypothetical scenario defined by a common tax rate on both contributions and end benefits, and by the absence of tax-free thresholds or other tax concessions. ${ }^{2}$ The significance of this point is that, under those assumptions, it would make no difference to forward looking governments and investors whether tax is levied on the way into the fund or on the way out. To see this, let $S_{i}$ be the superannuation contribution in period $i, r_{i}$ the return on the superannuation assets in period $i, t^{s}, t^{y}$ and $t^{b}$ the tax rates on contributions, income on fund assets, and end benefits respectively, $B_{n}$ the value of superannuation assets at retirement, and $n$ the number of periods of superannuation contributions. Assume that contributions are made at the start of each period and that tax is calculated on end of period values. The general expression for $B_{n}$ is

$$
B_{n}=\left(1-t^{s}\right)\left(\sum_{i=1}^{n} S_{i} \prod_{j=i}^{n}\left[1+r_{j}\left(1-t^{y}\right)\right]\right)\left(1-t^{b}\right)
$$

It is clear that TEE ( with $t^{s}=x, t^{t}=0, t^{b}=0$ ) and EET ( with $t^{s}=0, t^{t}=0, t^{b}=x$ ) would yield the same value of $B_{n}$. Of course in Australia and other countries this equivalence breaks down due to tax free thresholds on superannuation benefits and other complexities in the tax laws. For example, in the case of a threshold $\kappa$ as a proportion of benefits, (1) would be modified as follows:

$$
B_{n}=\left(1-t^{s}\right)\left(\sum_{i=1}^{n} S_{i} \prod_{j=i}^{n}\left[1+r_{j}\left(1-t^{y}\right)\right]\right)\left(1-[1-\kappa] t^{b}\right)
$$

in which case TEE and EET would not yield the same value of $B_{n}$ given the same tax rates. Currently in Australia $\kappa B_{n}=\$ 129,751$ (and, pre-J uly 2007, nominal $t^{s}=t^{y}=t^{b}=0.15$ ).

\section{References}

Anderson, F and L Allen (2006), 'Minchin flags super tax cut', The Australian Financial Review, 23 J anuary: 1.

Bloom, D., D. Canning and J. Sevilla (2003), The Demographic Dividend: A New Perspective on the Economic Consequences of Population Change, Rand, Santa Monica, CA.

\footnotetext{
${ }^{2}$ We are grateful to Peter Stemp for pointing this out.
} 
Commonwealth Government (2005), Government Response to Superannuation and Standards of Living in Retirement, available from http://www.aph.gov.au/ Senate/committee/superannuation_ctte/completed_inquiries/2002-04/living_standards/gov _response/government_response.pdf.

Costello, P. (2006), Budget Speech 2006-7, available from http://www.budget.gov.au/200607/speech/html/Speech.htm.

Guest, R. and I. MacDonald (2002), 'Superannuation, Population Ageing and Living Standards in Australia', Economic Analysis and Policy 32(1):19-33.

Freebairn, J. (1998), 'Compulsory Superannuation and Labour Market Responses', Australian Economic Papers 37(1):58-70.

Horne, J. (2002), 'Taxation of Superannuation in Australia: An Assessment of Reform Proposal', Unpublished Working Paper. Macquarie University.

IFSA (2007), 'Essential Super Stats, Volume 1', Investment and Financial Services Association, available from http://www.ifsa.com.au/documents/2\% 20Essential\% 20 Super\% 20Stats\% 20J anuary\% 202007.pdf.

Institute of Actuaries of Australia (2006), 'Tax-free Superannuation Benefits: A Future Revenue Problem?', available from http://www.actuaries.asn.au.

Jackson, N. and B. Felmingham (2004), 'The Demographic Gift in Australia', Agenda, 11(1):21-37.

Marris, S. (2006), 'Slash Tax on Super: Minchin', The Australian, 23 January: 1.

Productivity Commission (2005), 'Economic Implications of an Ageing Australia', Commonwealth of Australia, Canberra.

Senate Select Committee (2002), 'Superannuation and Standards of Living in Retirement: Report on the Adequacy of the Tax Arrangements for Superannuation and Related Policy', Commonwealth of Australia, Canberra.

Treasury (2006), 'A Plan to Simplify and Streamline Superannuation', available from http://www.budget.gov.au/2006-07/overview2/html/overview_01.htm.

Whitehouse, E. (1999), 'The Tax Treatment of Funded Pensions', Social Protection Discussion Paper Series, No. 9910, The World Bank, Washington DC.

The authors thank an anonymous referee, Peter Stemp and Graeme Wells (the Editor) for comments that have substantially improved this paper. The usual disclaimer applies. 